\title{
Whole Grains in the Renal Diet - Is It Time to Reevaluate Their Role?
}

\author{
Caroline Williams $^{\text {a }}$ Claudio Ronco $^{\text {b }}$ Peter Kotanko $^{a}$ \\ a Renal Research Institute, New York, N.Y., USA; ${ }^{\mathrm{b}}$ International Renal Research Institute, Vicenza, Italy
}

\section{Key Words}

Phytase $\cdot$ Phytate $\cdot$ Renal diet $\cdot$ Whole grains

\begin{abstract}
Organizations such as the National Kidney Foundation, the American Kidney Fund, the National Institute of Diabetes and Digestive and Kidney Diseases, and the US Department of Health and Human Services recommend not including whole grains as part of the renal diet. The rationale for this recommendation is the high phosphorus content in these foods. While the phosphorus content in whole grains may be indeed high, it is covalently bound to organic molecules (primarily phytate) and requires the enzyme phytase to be released and become available for absorption. While some phytase is contained in some whole grains (corn, oats, and millet have little to no phytase activity), the enzyme is decreased in milling, food preparation and over time. Since the human intestine does not express phytase, the enzyme required for the release of phosphorus from phytate is not present in the intestinal lumen when ingesting cooked food. Consequently, the bioavailability of phosphorus from whole grains is low. For the reasons presented here we believe that the 'grain ban' in the diet for kidney patients should be reconsidered. By doing this, the kidney diet would be enriched and it would provide needed fiber along with its health benefits, diversify the diet with low sodium choices, and possibly provide adequate protein without increasing phosphorous levels.
\end{abstract}

\section{Introduction}

In chronic kidney disease, phosphorus is not excreted from the body leading to secondary hyperparathyroidism and elevations in fibroblast growth factor-23. Hyperphosphatemia also leads to vascular calcification, which results in an increased risk for cardiovascular events and therefore has a negative effect on survival $[1,2]$. Abnormal mineral metabolism starts in early renal failure even before there are elevated serum phosphorus levels. In the early stages of chronic kidney disease, hyperphosphatemia is associated with a faster progression of chronic kidney disease. In animal studies, phosphate added to animal fodder was shown to accelerate aging, muscle and skin atrophy, progression of renal failure and cardiovascular calcifications [3]. In theory, a low phosphate diet and/or intake of phosphate binders help prevent these sequelae.

Despite these efforts and phosphorus removal by dialysis, patients still have difficulties controlling their phosphate levels. The renal diet is a very difficult diet to follow. Restrictions of sodium, potassium, fluid, and phosphorus leave little room to choose from especially healthy foods. The Kidney Outcome Quality Initiative guidelines of the National Kidney Foundation recommend patients on maintenance hemodialysis to consume $1.2 \mathrm{~g}$ protein/kg/day [4] This high protein recommendation is most likely to follow a greater phosphate intake. 
In the early days of the renal diet, phosphate restriction was not considered. The renal diet of the 1960 s concerned itself with a 60 -gram protein restriction, a potassium restriction, no added salt (except in cooking) and a fluid restriction of $500 \mathrm{ml}$ plus output. In the 1970s, protein was increased along with increased attention to phosphorus restriction with the emphasis on dairy, legumes, organ meats and eventually whole grains.

The two main sources of dietary phosphorus are 'organic phosphorus' and 'inorganic phosphorus' (table 1). Organic phosphorus is hydrolyzed in the intestinal track and then absorbed as inorganic phosphate. It is associated with protein-rich foods such as dairy, meat, fish, and eggs. Another source of organic phosphorus is that bound to phytate. Phytate-rich foods include whole grain, legumes and nuts. The phosphorus bound to phytate in whole grains is not so easily hydrolyzed in the gut since humans lack the enzyme phytase. The organicbound phosphorus of meat and dairy has a gastrointestinal absorption rate of $40-60 \%[5,6]$ whereas that of phosphorus bound to phytate is $20-50 \%$ [7]. The other source of phosphate is 'inorganic phosphorus', which is found primarily in processed foods; it is added to enhance appearance and shelf life. The complexity of phosphate in food is further increased by phosphate enhancers ('additives') added to meat. Phosphate enhancers are inorganic phosphates which are avidly absorbed in the intestines (bioavailability of 90-100\%) [6] and therefore may substantially contribute to the phosphate load. In the US, these phosphate additives in meats are not indicated on food labels, so people have no way of knowing if and how much phosphates are added [8]. Phosphate additives are used extensively in the food industry. They are common in popular less expensive foods and therefore can contribute to the phosphate load furthermore. Despite the high content of phosphorus in plant foods, its actual intestinal absorption may be less than from animal-based sources when expressed per gram of protein. Even though it is known that phosphates in whole grains are bound to phytate and unavailable for human intestinal absorption, the content of phosphate in whole grains seemed to hold more weight. Still, to this day, the American Kidney Foundation, the American Kidney Fund, the Academy of Nutrition and Dietetics, and the Mayo Clinic all recommend avoiding whole grains due to its phosphate content. However, as we will show in this present work, this notion is based solely on the content of phosphorus in these foods and ignores the importance of phosphorus bioavailability.
Table 1. Composition of nutrients

\begin{tabular}{|c|c|c|c|c|c|}
\hline \multirow[t]{2}{*}{ Nutrient } & \multirow[t]{2}{*}{ Size, $g$} & \multicolumn{4}{|c|}{ Amount per $100 \mathrm{~g}$} \\
\hline & & $\begin{array}{l}\text { energy, } \\
\text { calories }\end{array}$ & $\begin{array}{l}\mathrm{PO}_{4}, \\
\mathrm{mg}\end{array}$ & $\begin{array}{l}\mathrm{K}, \\
\mathrm{mg}\end{array}$ & $\begin{array}{l}\text { fiber, } \\
\mathrm{g}\end{array}$ \\
\hline \multicolumn{6}{|l|}{ Whole grains } \\
\hline Barley, pearl & 100 & 352 & 221 & 280 & 16 \\
\hline Brown rice & 100 & 370 & 333 & 223 & 4 \\
\hline Bulgur & 100 & 342 & 300 & 410 & 18 \\
\hline Buckwheat $^{1}$ & 100 & 342 & 319 & 320 & 10 \\
\hline Farro & 100 & 340 & 406 & 426 & 10 \\
\hline Millet & 100 & 378 & 285 & 195 & 8.5 \\
\hline Oats & 100 & 389 & 523 & 429 & 11 \\
\hline Quinoa $^{1}$ & 100 & 368 & 457 & 563 & 7 \\
\hline Spelt & 100 & 338 & 401 & 388 & 11 \\
\hline Wheat berries & 100 & 327 & 288 & 363 & 12 \\
\hline Wild rice & 100 & 357 & 433 & 427 & 6 \\
\hline Whole grain flour & 100 & 332 & 323 & 394 & 13 \\
\hline Chia seed $^{1}$ & 100 & 489 & 860 & 407 & 34 \\
\hline \multicolumn{6}{|l|}{ Nuts } \\
\hline Almonds & 100 & 579 & 481 & 733 & 13 \\
\hline Peanuts, Valencia & 100 & 570 & 336 & 332 & 9 \\
\hline Walnuts & 100 & 654 & 346 & 441 & 7 \\
\hline Cashews & 100 & 553 & 593 & 660 & 3 \\
\hline Macadamia & 100 & 718 & 188 & 368 & 9 \\
\hline Pine nuts & 100 & 673 & 575 & 597 & 4 \\
\hline \multicolumn{6}{|l|}{ Dairy $^{1}$} \\
\hline Cheddar cheese & 100 & 403 & 512 & 98 & 0 \\
\hline Amer. cheese spread & 100 & 176 & 931 & 250 & 0 \\
\hline Swiss cheese & 100 & 380 & 567 & 77 & 0 \\
\hline \multicolumn{6}{|l|}{ Seafood ${ }^{1}$} \\
\hline Shrimp & 100 & 99 & 237 & 259 & 0 \\
\hline Frozen shrimp & 100 & 99 & $\mathrm{n} / \mathrm{a}^{2}$ & $\mathrm{n} / \mathrm{a}$ & 0 \\
\hline Atlantic cod & 100 & 82 & 203 & 413 & 0 \\
\hline \multicolumn{6}{|l|}{ Meat and eggs ${ }^{1}$} \\
\hline Chicken breast & 100 & 165 & 228 & 256 & 0 \\
\hline Beef & 100 & 265 & 201 & 326 & 0 \\
\hline Egg, large & 100 & 142 & 191 & 134 & 0 \\
\hline \multicolumn{6}{|l|}{ Beverages } \\
\hline Cola & $240 \mathrm{ml}$ & 136 & 37 & 7 & 0 \\
\hline Ginger ale & $240 \mathrm{ml}$ & 124 & 0 & 4 & 0 \\
\hline
\end{tabular}

The size refers to the mass (g) of dry (uncooked) foodstuff. Phosphate bioavailability varies between foodstuff, in whole grains and nuts it is 20-50\%; in dairy, seafood (except for frozen shrimp), meat, and eggs it is $40-60 \%$, and in processed food (sodas, cheese spread, and frozen shrimp) it is $90-100 \%$.

${ }^{1}$ Complete protein (containing all 8 essential amino acids).

${ }^{2}$ Sodium tripolyphosphate is added to frozen shrimp to retain its moisture and to de-shell the shrimp [37]. 
Fig. 1. Myo-inositol-1,2,3,4,5,6-hexakisphosphate (Ins P6 or phytic acid) is a storage form of phosphorus in whole grains. It is converted into inositol by the enzyme phytase. Most whole grain products are processed or heat treated during food production or preparation, procedures which inactivate phytases, resulting in very low phytase levels in the human intestines Courtesy of Cecil W. Forsberg, University of Guelph, Ont., Canada.

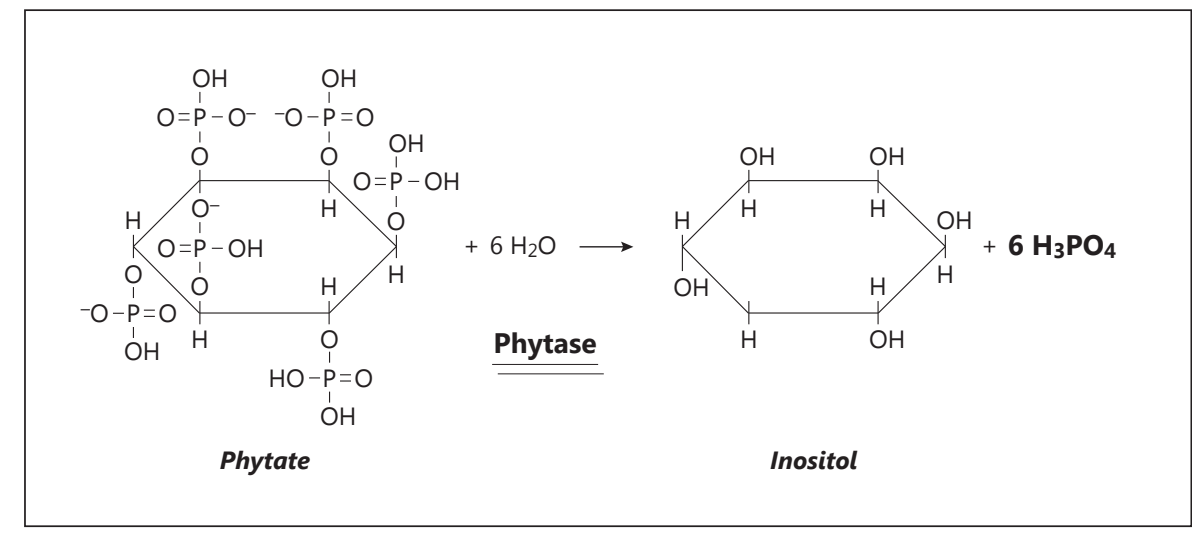

\section{Biochemistry and Physiology of Organic Phosphate in Whole Grains}

Myo-inositol-1,2,3,4,5,6-hexakisphosphate (Ins P6 or phytic acid, fig. 1) is the major storage form of phosphorus, energy and minerals in seeds and other plant tissues. During germination, phytate is hydrolyzed, and phosphate and other minerals become available for the development of seedlings. Phytate is heat stable [9] but can be degraded in food processing, such as fermentation or the aid of exogenous phytases, which can reduce phytate [10, 11]. Sourdough fermentation has been shown to reduce phytate more effectively than yeast-fermented bread [12]. Phytases (myo-inositol hexaphosphate phosphohydrolase: EC 3.1.3.8 and EC 3.1.3.26) are a subgroup of phosphorolytic enzymes that catalyze the release of phosphate from phytate (fig. 1) and hydrolyzes the complexes formed by phytate and metal ions or other cations, rendering them more soluble, ultimately improving and facilitating their intestinal absorption. Phytases are found in plants (EC3.1.3.26), microorganisms (EC3.1.3.8) and in animal tissue [13-15]. Exogenous phytases are mostly used in animal feed to reduce phosphate pollution of animal waste. The World Health Organization has only recently established that the 3-phytase from Aspergillus niger is safe for use in and with food for humans and for consumption. Nevertheless, most whole grain products are processed or heat treated during food production or preparation, and in these processes, phytases are most likely inactivated to a large extent [16]. Daily phytate consumption varies among people around the world. Western style diet varies from about $0.3-2.6 \mathrm{~g} /$ day to a global range of $0.18-4.57 \mathrm{~g} /$ day [17]. Vegetarian diets naturally have higher consumption of phytate. Phytate consumption has been linked to beneficial properties, including being a natural antioxidant [18], having anticancer actions [19], preventing renal stones [20], and improving blood cholesterol and blood glucose control [21].

\section{Whole Grains in Human Food and the Renal Diet}

Whole grains have been part of the human diet for about 10,000 years. In many cultures, whole grains are the staple of diets. They can provide $60-70 \%$ of total caloric intake. Rice has been around for the past 7,000-10,000 years. Prior to the Industrial Revolution, rice as well as other grains were originally hulled/polished and or ground manually, which meant that it was only done roughly, leaving a lot of the bran still attached. The taste for polished white rice began about 150 years soon after the introduction of mechanical rice mills. Traders preferred this white form without its nutritious bran and germ because it was lighter to export and it would not go rancid, which meant more profits. In addition, white rice is an easily digested carbohydrate that requires consuming more to feel fuller.

The mechanisms responsible for the benefits of whole grains are not well understood, but some responsibility may fall on the bacterial fermentation of indigestible components of the whole grain [22]. Whole grains take longer to digest (therefore slowing gastric emptying) and deters excessive food intake. Whole grains are rich in fiber, B vitamins, antioxidants, minerals, phytochemicals, lignans (polymers of phenylpropane), and phenolic compounds [23]. They have been linked to reducing the risk of obesity, insulin resistance, type II diabetes, heart disease, hypertension, and cancer [24-28]. Whole grains high in viscous fiber (oats and barley) are believed to decrease serum low-density lipoprotein cholesterol and im- 
prove glucose and insulin responses by increasing the viscosity of the digesta and binding to bile acids in the small intestine. This contributes to a decrease in sugar and lipid absorption [23]. Grains high in insoluble fiber (wheat) moderately lower glucose and blood pressure but also have a prebiotic effect $[29,30]$. The bacterial fermentation of indigestible components of whole grains in the gastrointestinal track is being considered for being responsible for anti-inflammatory action as well as other metabolic benefits [31]. In a recent study, subjects who consumed a whole grain diet increased the diversity and the number of intestinal microflora. This short-term intake of whole grains demonstrated an alteration in the intestinal microbiota revealing metabolic and immunological improvements in healthy individuals [32]. Since whole grains are beneficial in people with cardiovascular disease, diabetes, and obesity as well as in healthy people, one may speculate that whole grains also exert benefits in patients with kidney disease, in particular those with diabetes, cardiovascular disease and obesity as comorbidities.

There are some potential disadvantages to implementing whole grains in the renal diet. For one thing most people are not familiar with consuming whole grains other than whole wheat bread and oatmeal. Even those foods may not be the norm for most. The Western diet is characterized by a high intake of red meats, refined sugars, high fat, refined grains and processed foods. Refined grains represent $85 \%$ of the grains consumed and $20 \%$ of total energy intake. Whole grains contribute only $3.5 \%$ of total energy. The average fiber intake is $15.1 \mathrm{~g} /$ day, which is considerably lower than the recommended value of 25 $30 \mathrm{~g} /$ day $[33,34]$. Whole grains require cooking, which may take up to $1 \mathrm{~h}$. This may deter people who want fast- er meals. Unfamiliarity with the variety of grains and the time restraints can make implementing whole grains in kidney patients challenging. Some may argue that whole grains do not provide a protein source with all nine essential amino acids (incomplete protein). Complete proteins come from animal-based products (meat, poultry, dairy, eggs, and fish, for example), soy, chia seed, and quinoa (a grain). However, incomplete proteins can be combined in meals to make a complete protein. An example is combining rice and beans or peanut butter and toast. Most whole grains have a low content of the essential amino acid lysine. However, lysine can be complemented with nuts low in potassium, such as walnuts, cashews, pine nuts, or peanuts. It is sufficient to eat these complementary proteins within $24 \mathrm{~h}$ in order to build protein. Incomplete proteins come from plant-based foods, such as beans, rice, grains, and legumes [35].

\section{Conclusion}

We suggest that the role of whole grains in the diet of patients with renal disease should be reconsidered. There are data suggesting that the bioavailability of phosphate from whole grains is low, despite their high phosphate content. This low bioavailability is related to the lack of phytase, an enzyme required to release phosphorus from phytate, the main storage form of phosphate in whole grains. Considering whole grains for the kidney diet, the diet would be enriched and provide needed fiber along with its health benefits, diversify the diet with low sodium choices, and possibly provide adequate protein without increasing phosphorous levels.

\section{References}

1 Stevens LA, et al: Calcium, phosphate, and parathyroid hormone levels in combination and as a function of dialysis duration predict mortality: evidence for the complexity of the association between mineral metabolism and outcomes. J Am Soc Nephrol 2004;15:770779.

2 Young EW, et al: Magnitude and impact of abnormal mineral metabolism in hemodialysis patients in the Dialysis Outcomes and Practice Patterns Study (DOPPS). Am J Kidney Dis 2004;44(suppl 2):34-38.

-3 Block GA, et al: Mineral metabolism, mortality, and morbidity in maintenance hemodialysis. J Am Soc Nephrol 2004;15:2208-2218.
4 National Kidney Foundation: K/DOQI clinical practice guidelines for bone metabolism and disease in chronic kidney disease. Am J Kidney Dis 2003;42(suppl 3):S1-S201.

5 Kayne LH, et al: Analysis of segmental phosphate absorption in intact rats. A compartmental analysis approach. J Clin Invest 1993; 91:915-922.

6 Lei XG, Porres JM: Phytase enzymology, applications, and biotechnology. Biotechnol Lett 2003;25:1787-1794.

7 Sullivan C, et al: Effect of food additives on hyperphosphatemia among patients with end-stage renal disease: a randomized controlled trial. JAMA 2009;301:629-635.
8 Riccioni G, et al: Dietary fibers and cardiometabolic diseases. Int J Mol Sci 2012;13: 1524-1540.

-9 Schlemmer U, Muller H, Jany KD: The degradation of phytic acid in legumes prepared by different methods. Eur J Clin Nutr 1995; 49(suppl 3):S207-S210.

10 Fredrikson M, et al: Phytate degradation by micro-organisms in synthetic media and pea flour. J Appl Microbiol 2002;93:197-204.

-11 Sandberg AS, Hulthen LR, Turk M: Dietary Aspergillus niger phytase increases iron absorption in humans. J Nutr 1996;126:476-480. 
12 Lopez HW, et al: Making bread with sourdough improves mineral bioavailability from reconstituted whole wheat flour in rats. $\mathrm{Nu}$ trition 2003;19:524-530.

-13 Bitar K, Reinhold JG: Phytase and alkaline phosphatase activities in intestinal mucosae of rat, chicken, calf, and man. Biochim Biophys Acta 1972;268:442-452.

$>14$ Irving GC, Cosgrove DJ: Inositol phosphate phosphatases of microbiological origin. Observations on the nature of the active centre of a bacterial (Pseudomonas sp.) phytase. Aust J Biol Sci 1971;24:559-564.

15 Powar VK, Jagannathan V: Phytase from Bacillus subtilis. Indian J Biochem 1967;4:184185.

16 Schlemmer U, et al: Phytate in foods and significance for humans: food sources, intake, processing, bioavailability, protective role and analysis. Mol Nutr Food Res 2009; 53(suppl 2):S330-S375.

17 Reddy NR, Sathe SK: Food phytates. Boca Raton, CRC Press, 2002, pp xv, 258.

$\checkmark 18$ Graf E, Empson KL, Eaton JW: Phytic acid. A natural antioxidant. J Biol Chem 1987;262: 11647-11650.

19 Shamsuddin AM: Inositol phosphates have novel anticancer function. J Nutr 1995; 125(suppl 3):725S-732S.

20 Grases F, Costa-Bauza A: Phytate (IP6) is a powerful agent for preventing calcifications in biological fluids: usefulness in renal lithiasis treatment. Anticancer Res 1999;19:37173722 .
21 Thompson LU, Button CL, Jenkins DJ: Phytic acid and calcium affect the in vitro rate of navy bean starch digestion and blood glucose response in humans. Am J Clin Nutr 1987;46: 467-473.

22 Nilsson AC, et al: Effect of cereal test breakfasts differing in glycemic index and content of indigestible carbohydrates on daylong glucose tolerance in healthy subjects. Am J Clin Nutr 2008;87:645-654.

23 Misra A, Rastogi K, Joshi SR: Whole grains and health: perspective for Asian Indians. J Assoc Physicians India 2009;57:155-162.

24 Liu S, et al: Whole-grain consumption and risk of coronary heart disease: results from the Nurses' Health Study. Am J Clin Nutr 1999; 70:412-419.

25 Fung TT, et al: Whole-grain intake and the risk of type 2 diabetes: a prospective study in men. Am J Clin Nutr 2002;76:535-540.

26 Liu S, et al: Relation between changes in intakes of dietary fiber and grain products and changes in weight and development of obesity among middle-aged women. Am J Clin Nutr 2003;78:920-927.

27 Jensen MK, et al: Intakes of whole grains, bran, and germ and the risk of coronary heart disease in men. Am J Clin Nutr 2004;80:14921499 .

28 Nettleton JA, et al: Incident heart failure is associated with lower whole-grain intake and greater high-fat dairy and egg intake in the Atherosclerosis Risk in Communities (ARIC) study. J Am Diet Assoc 2008;108:1881-1887.

$\checkmark 29$ Flint HJ, et al: Interactions and competition within the microbial community of the human colon: links between diet and health. Environ Microbiol 2007;9:1101-1111.

30 Louis P, et al: Understanding the effects of diet on bacterial metabolism in the large intestine. J Appl Microbiol 2007;102:11971208.
31 Nilsson AC, et al: Including indigestible carbohydrates in the evening meal of healthy subjects improves glucose tolerance, lowers inflammatory markers, and increases satiety after a subsequent standardized breakfast. J Nutr 2008;138:732-739.

32 Martinez I, et al: Gut microbiome composition is linked to whole grain-induced immunological improvements. ISME J 2013;7:269280

33 Gerrior S, Bente L, Center for Nutrition Policy and Promotion: Nutrient Content of the U.S. Food Supply, 1909-99: A Summary Report. Home Economics Research Report. 2002, Washington, Center for Nutrition Policy and Promotion, US Department. of Agriculture, pp i, 22.

34 US Department of Agriculture Research Service. Data Tables: Results from USDA’s 199496 Continuing Survey of Food Intakes by Individuals and 1994-96 Diet and Health Knowledge Survey. ARS Food Surveys Research Group, 1997. http://www.barc.usda. gov/bhnrc/foodsurvey/home.htm (accessed May 11, 2004).

35 Norris J, Messina V: Vegan for Life: Everything You Need to Know to Be Healthy and Fit on a Plant-Based Diet. Cambridge, Da Capo Press, 2011, pp xix, 283.

36 USDA National Database for standard Reference, Release 29. http://www.ars.usda.gov/ nutrientdata (accessed December 2011).

37 http://www.foodadditivies.org/phosphates/ phosphates_used_in food.html. 